Vol. 5, No. 2, 2019

\author{
Karam Shixaliyev ${ }^{1}$, Ibrahim Abbasov ${ }^{2}$, Khaver Sadig ${ }^{3}$ \\ ${ }^{1}$ Department of Organic Substances and Technologies of High Molecular Connections, Azerbaijan State Oil and \\ Industry University, Baku AZ1010, Azerbaijan, 20 Azadlig Avenue, E-mail: kerem_shixaliyev@mail.ru \\ ${ }^{2}$ Department of Physics, Azerbaijan State Oil and Industry University, Baku AZ1010, Azerbaijan, 20 Azadlig \\ Avenue, E-mail: ibrahimabbasov179@gmail.com \\ ${ }^{3}$ Department of Physics, Azerbaijan State Oil and Industry University, Baku AZ1010, Azerbaijan, 20 Azadlig
} Avenue, E-mail: sadig.xaver@gmail.com

\title{
THEORY AND PRACTICE OF OBTAINING COMPOSITE MATERIALS BASED ON POLYMER BLENDS
}

Received: May 22, 2019 / Revised: August 15, 2019 / Accepted: August 30, 2019

(C) Shixaliyev K., Abbasov I., Sadig Kh., 2019

\begin{abstract}
The regularities of the thermodynamic compatibility of various industrially produced polyolefins and heterochain polymers and the possibility of obtaining composite materials based on their mixtures with significantly increased performance properties based on existing production facilities and process equipment have been identified.

The methods have been developed for the chemical and physical modification of individual polymers, their mixtures to improve the performance properties of composite materials; including the method of modification of polyethylene, which made it possible to significantly increase its thermal stability in air and in vacuum, anti-corrosion properties.

The effectiveness of the use in composite materials of the petroleum resin PPC intended to produce the products operated under conditions of increased mechanical wear, temperatures, pressures and deformations.

Developed composite materials based on mixtures of PVC, TPU, CCPE+PVC, CCPE+PU, LDPE+BR, technology of their manufacturing and processing, application of new efficient products with extreme operating conditions: injection molded tires for agricultural machines, casing stabbing baskets, nuclear magnetic logging probes, scrapers and bucket elevators, sealing rings for pneumatic radiators, indented surface of the grain cleaning machines.
\end{abstract}

Keywords: compatibility, injection molded tires, processing, solubility parameter, chlorocarboxylated polyethylene (CCPE), polyvinyl chloride (PVC), composition, obtaining mixtures of polymers.

\section{Introduction}

The problem of obtaining polymer composites with the necessary properties for working under extreme conditions at the present time is solved in two ways: by synthesis new types of polymers and by creating polymer compositions, where the properties of the individual components additively complement each other.

The scientific and technological progress of manufacturing imposes more and new stringent requirements on the polymer products, and the demand of industry for new materials is constantly increasing. Thus, the development of various polymer composites, greatly simplifying the technology of their production and processing, reducing the cost of obtaining materials with the necessary sets of properties is extremely relevant under current technological conditions.

In the polymer industry there is large-tonnage production of individual polyolefins and heterochain polymers, on the one hand to permit the realization of a certain range of performance properties of polymer products, and on the other hand, the constant development of technology requires expanding the range of application of polymer products increasing their technical level. This contradiction put forward as one of 
the most important economic problems - the need to develop industrial technology to produce new types of composite materials with significantly enhanced performance capabilities on the basis of manufactured polyolefins and heterochain polymers, to offer the production of new high-performance products using existing production facilities and process equipment.

\section{Materials}

For the experiments in this work were used commercially available polymers:

- isotactic polypropylene (PP; P5000 / Vestolen GmbH);

- nitrile rubber (NBR; Perbunan NT 3465 / Bayer AG);

- ethylene-propylene-diene polymer (EPDM; Buna EP G 5450).

Several types of promoters for processing (PRMs) were obtained from RheinChemie (Mannheim).

Polyolefin thermoplastic elastomers were obtained on the basis of ethylene-propylene elastomers and high-density polyethylene by two methods: in the first case sulfur-containing compounds (altax, sulfur) were used as a modifying agent, in the second case - TLV.

A series of thermoplastic elastomers was obtained by combining the initial polymer components in the melt on rollers at a roll temperature of $433 \ldots 453 \mathrm{~K}$ with a gap between them $\sim 0,2 \mathrm{~mm}$. After melting the crystalline thermoplastic, EPDM and structuring agents were added. To achieve good homogenization, rolling was carried out for 25 minutes.

Formulation of the compositions had the following composition (pts. wt.): EPDM - 100; HDPE - 10...80; dicumyl peroxide 1...2. B series of thermoplastic elastomers were obtained similarly to the A series of thermoplastic elastomers according to the following formulation (pts. wt.): EPDM - 100; HDPE - 10...80; altax - 1.8; sulfur - 2.0.

There are a number of fundamental approaches to the manufacture of polymer mixtures among which the method of mixing thermoplastic polymers, carried out on an extruder or roll mills, compares favorably with simplicity of technology. Despite a range of limitations associated with the stability of the mixture throughout the entire manufacturing cycle of the specified method, it was possible to obtain a number of mixtures of TPU with other thermoplastics. Thus, by blending TPU with PVC, a material obtained combines the impact resistance and abrasion resistance of TPU with rigidity and high modulus of elasticity of PVC. At the same time the resulting composite is cheaper than pure TPU.

\section{Compatibility calculation for the system butyl rubber - low density polyethylene (BR-LDPE) at temperature $298 \mathrm{~K}$}

We calculate the solubility parameters of individual components of the mixture using tabular values of the Small molar attraction constants of various chemical groups, taking into account the density of BR at $298 \mathrm{~K} \rho=0.92 \cdot 10^{3} \mathrm{~kg} / \mathrm{m}^{3}$, the isoprene content $5 \%$, the density of LDPE $\rho=0.96 \cdot 10^{3} \mathrm{~kg} / \mathrm{m}^{3}$. The calculation does not take into consideration the distribution of end groups and molecular-mass distributions. The formula for $\mathrm{BR}(n=0.95 ; m=0.05)$ is:

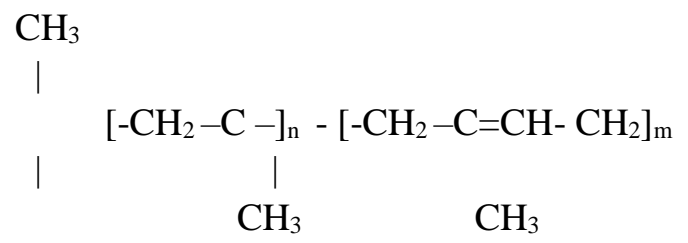

Molar attraction constants of isoprene:

$$
\begin{gathered}
\sum F=133 \cdot 2+93+2 \cdot 14+28=415 ; \\
M=5 \cdot 12+8 \cdot 1=68 .
\end{gathered}
$$

Molar attraction constants of isobutylene:

$$
\begin{gathered}
\sum F-\mathrm{CH}_{2}-\mathrm{CH}_{3} \quad \backslash \\
\mathrm{C} \\
\sum F=133+2 \cdot 214-93=468 ;
\end{gathered}
$$




$$
M=12 \cdot 4+5 \cdot 1=53 \text {. }
$$

Then the solubility parameter of BR:

The solubility parameter of LDPE:

$$
\delta_{B R}=\frac{0.92}{0.95} \cdot \frac{468}{53}+0.05 \cdot \frac{415}{68}=8.9 .
$$

$$
\begin{gathered}
\sum F=133 ; \\
M=1 \cdot 12+2 \cdot 1=14 ; \\
\delta_{L D P E}=0.96 \cdot \frac{133}{14}=9.12 .
\end{gathered}
$$

The calculation of the interaction parameter between polymers have been performed by the Hildebrand equation; $R$ is the gas constant equal to $1,987 \mathrm{kcal} / \mathrm{deg}^{-1} \mathrm{~mole}^{-1} ; T$ is the temperature in degrees Kelvin and $V_{r}$ is the reference volume in $\mathrm{cm}^{3} /$ mole conveniently taken to be $100 \mathrm{~cm}^{3} / \mathrm{mole}$.

For this value of $V_{r}$ and temperature $298 \mathrm{~K}$, the Hildebrand equation takes the form:

$$
\chi_{A B}=\frac{\left(\delta_{A}-\delta_{B}\right)^{2}}{G} \text {. }
$$

In this case:

$$
\chi_{B R-L D P E}=\frac{(9.12-8.9)^{2}}{6}=0.081 .
$$

The following equation is used to calculate the critical $\chi_{B R-L D P E}$ :

$$
\chi_{c r}=\frac{1}{2} \cdot\left(\frac{1}{\chi_{A}^{1 / 2}}+\frac{1}{\chi_{B}^{1 / 2}}\right)^{2}
$$

which involves the degree of polymerization of each polymer in terms of the reference volume $V_{r}$. The degree of polymerization can be calculated based on the validity of the degree of polymerization $\chi$, if the molar volume of the repeating unit of the polymer is known, by the equation:

$$
\chi_{A}=\left(\frac{\bar{V}}{V_{r}}\right)_{x} .
$$

A fairly good approximation is obtained from the relation:

$$
\chi_{A}=\frac{M_{A}}{100},
$$

where $M_{A}$ is the molecular weight of polymer.

Thus, we have:

$$
\begin{gathered}
\chi_{B R}=\frac{350000}{100}=3500 ; \\
\chi_{L D P E}=\frac{300000}{100}=3000 .
\end{gathered}
$$

Hence, using the equation for calculating the critical value

$$
\left(\chi_{B R-L D P E}\right)_{c r}=\frac{1}{2} \cdot\left(\frac{1}{3500^{1 / 2}}+\frac{1}{3000^{1 / 2}}\right)^{2}=6.18 \cdot 10^{-4}
$$

we determine the probability of phase separation origin, for which purpose we calculate $\chi_{B R-L D P E}$ for various phase compositions. The results are summarized in Table 1.

As is clear, with a decrease in the concentration of any component in the mixture, the spinodal solubility parameter increases and LDPE dissolves in BR much better than BR in LDPE. The concentrations were determined by variational method at which absolute combination is possible. This is $0.08 \mathrm{wt} \%$ for LDPE and $0.06 \mathrm{wt} \%$ for BR. 
The solubility parameters of the BR-LDPE system

\begin{tabular}{|c|c|c|c|}
\hline$\Phi_{B R}$ & $\left(\chi_{B R-L D P E}\right)_{s p}$ & $\Phi_{B R}$ & $\left(\chi_{B R-L D P E}\right)_{s p}$ \\
\hline 0.00 & - & 0.55 & $6.3 \cdot 10$ \\
\hline 0.05 & $3.03 \cdot 10$ & 0.60 & $6.55 \cdot 10$ \\
\hline 0.10 & $1.61 \cdot 10$ & 0.65 & $6.96 \cdot 10$ \\
\hline 0.15 & $1.15 \cdot 10$ & 0.70 & $7.60 \cdot 10$ \\
\hline 0.20 & $9.23 \cdot 10$ & 0.75 & $8.57 \cdot 10$ \\
\hline 0.25 & $7.94 \cdot 10$ & 0.80 & $1.01 \cdot 10$ \\
\hline 0.30 & $7.14 \cdot 10$ & 0.85 & $1.28 \cdot 10$ \\
\hline 0.35 & $6.65 \cdot 10$ & 0.90 & $1.83 \cdot 10$ \\
\hline 0.40 & $6.35 \cdot 10$ & 0.95 & $3.48 \cdot 10$ \\
\hline 0.45 & $6.20 \cdot 10$ & 1.00 & - \\
\hline 0.50 & $6.19 \cdot 10$ & - & - \\
\hline
\end{tabular}

Thus, the calculation method shows that the BR-LDPE system is practically incompatible.

To find the critical point of the system in the phase diagram, it is necessary to calculate the $G_{m i x}$ for different composition of the system. The calculation was performed at $T=298 \mathrm{~K}$, the results of which have been summarized in Table 2 .

Table 2

\section{Heat of mixing BR-LDPE}

\begin{tabular}{|c|c|c|c|}
\hline$\Phi_{B R}$ & $G_{m i x}$ & $\Phi_{B R}$ & $G_{\text {mix }}$ \\
\hline 0.00 & - & 0.55 & $3.42 \cdot 10$ \\
\hline 0.05 & $6.58 \cdot 10$ & 0.60 & $3.33 \cdot 10$ \\
\hline 0.10 & $1.25 \cdot 10$ & 0.65 & $3.16 \cdot 10$ \\
\hline 0.15 & $1.77 \cdot 10$ & 0.70 & $2.91 \cdot 10$ \\
\hline 0.20 & $2.22 \cdot 10$ & 0.75 & $2.60 \cdot 10$ \\
\hline 0.25 & $2.60 \cdot 10$ & 0.80 & $2.22 \cdot 10$ \\
\hline 0.30 & $2.91 \cdot 10$ & 0.85 & $1.77 \cdot 10$ \\
\hline 0.35 & $3.16 \cdot 10$ & 0.90 & $1.25 \cdot 10$ \\
\hline 0.40 & $3.33 \cdot 10$ & 0.95 & $6.58 \cdot 10$ \\
\hline 0.45 & $3.42 \cdot 10$ & 1.00 & - \\
\hline 0.50 & $3.46 \cdot 10$ & - & - \\
\hline
\end{tabular}

The calculated data show that the so-called symmetric case with the lower critical solution temperature (LCST) is observed for the BR-LDPE system. Based on the additivity principle, we have $T_{c r}=503 \mathrm{~K}$.

Thus, from the above calculation conclusions can be drawn:

1. The BR-LDPE system is practically incompatible;

2. The combination is possible at the concentration of BR in LDPE up to $0.06 \%$ and at the concentration of LDPE up to $0.08 \%$.

To compare the compatibility of polymer blends depending on the polarity of the components, the compatibility parameters for the system of polar components PVC and TPU were calculated (compared with the non-polar system LDPE-BR).

\section{Compatibility calculation for the system polyvinyl chloride - thermoplastic polyurethane (PVC-TPU) at temperature $298 \mathrm{~K}$}

We calculate the solubility parameters of individual components of the mixture using tabular values of the Small molar attraction constants for different chemical groups, taking into account the density of 
PVC at $298 \mathrm{~K}\left(\rho=1.41 \cdot 10^{3} \mathrm{~kg} / \mathrm{m}^{3}\right)$. In the calculation, we will consider the distribution of end groups due to the insignificance of their number and without taking into account the molecular weight distribution.

Unit link of PVC - $\left[-\mathrm{CH}_{2}-\mathrm{CHCl}-\right]_{\mathrm{n}}$.

Molar constants of attraction:

$$
\begin{gathered}
-\mathrm{CH}_{2}--\mathrm{CH}=\mathrm{Cl}- \\
\sum F=133+28+270=431 ; \\
M=12 \cdot 2+1 \cdot 3+35.5=62.5 .
\end{gathered}
$$

Then the solubility parameter of PVC will be:

$$
\delta_{P V C}=1.41 \cdot \frac{431}{62.5}=9.72 .
$$

The solubility parameter of TPU, taking into account the fact that the density of TPU at $298 \mathrm{~K}$ is equal to $\rho_{298}=1.1 \cdot 10^{3} \mathrm{~kg} / \mathrm{m}^{3}$.

Unit link of TPU

$$
\begin{gathered}
{\left[-\left(\mathrm{CH}_{2}\right)_{6}-\mathrm{OCOHN}-\left(\mathrm{CH}_{2}\right)_{4}-\right]_{\mathrm{n}}} \\
-\left(\mathrm{CH}_{2}\right)_{6}--\mathrm{COO}--\mathrm{NH}--\left(\mathrm{CH}_{2}\right)_{4} \\
\sum F=133 \cdot 6+310+180+133 \cdot 4=1820 ; \\
M=12 \cdot 11+1 \cdot 21+16 \cdot 2+14=199 ; \\
\delta_{T P U}=1.10 \cdot \frac{1820}{199}=10.06 .
\end{gathered}
$$
equation:

The calculation of the interaction parameter between the polymers in the system is performed by the

$$
\chi_{A B}=\frac{V_{r}}{R \cdot T} \cdot\left(\delta_{A}-\delta_{B}\right)^{2},
$$

where $R$ is the gas constant equal to $1.987 \mathrm{kcal} / \mathrm{deg}^{-1} \mathrm{~mole}^{-1} ; T$ is the temperature in degrees Kelvin and $V_{r}$ is the reference volume in $\mathrm{cm}^{3} /$ mole conveniently taken to be $100 \mathrm{~cm}^{3} /$ mole. Thus, for $T=298 \mathrm{~K}$, the equation becomes:

$$
\chi_{A B}=\frac{\left(\delta_{A}-\delta_{B}\right)^{2}}{G} .
$$

In this case, for the system PVC-TPU we have:

$$
\delta_{P V C-T P U}=\frac{(10.06-9.72)^{2}}{6}=0.019 .
$$

To calculate the critical value $\left(\chi_{P V C-T P U}\right)_{c r}$ the following equation is used:

$$
\chi_{c r}=\frac{1}{2} \cdot\left(\frac{1}{\chi_{A}^{1 / 2}}+\frac{1}{\chi_{B}^{1 / 2}}\right)^{2},
$$

which involves the degree of polymerization of each polymer in terms of the reference volume $V_{r}$. The degree of polymerization can be calculated based on the validity of the degree of polymerization $\chi$, if the molar volume of the repeating unit of the polymer is known, by the equation:

$$
\chi_{A}=\left(\frac{\bar{V}}{V_{r}}\right)_{x} .
$$

A fairly good approximation is obtained from the relation:

$$
\chi_{A}=\frac{M_{A}}{100},
$$

where $M_{A}$ is the molecular weight of polymer.

Thus, we have: 


$$
\begin{aligned}
& \chi_{P V C}=\frac{90000}{100}=900 ; \\
& \chi_{T P U}=\frac{18000}{100}=180 .
\end{aligned}
$$

Hence, using the equation for calculating the critical value

$$
\left(\chi_{P V C-T P U}\right)_{c r}=\frac{1}{2} \cdot\left(\frac{1}{\left(\chi_{A}\left(\Phi_{A} / G_{p}\right)\right)^{1 / 2}}+\frac{1}{\left(\chi_{B}\left(\Phi_{B}\right)_{s p}\right)^{1 / 2}}\right)^{2}
$$

we determine the probability of phase separation origin, for which purpose we calculate $\left(\chi_{P V C-T P U}\right)_{s p}$ for various phase compositions. The results are summarized in Table 3.

Table 3

Values of the spinodal interaction parameter for different phase compositions:

\begin{tabular}{|c|c|c|c|c|c|}
\hline Item no. & PVC & $\left(\chi_{P V C-T P U}\right)_{s p}$ & Item no. & PVC & $\left(\chi_{P V C-T P U}\right)_{s p}$ \\
\hline 1. & 0.00 & - & 12. & 0.55 & $6.67 \cdot 10^{-2}$ \\
\hline 2. & 0.05 & $2.78 \cdot 10^{-3}$ & 13. & 0.60 & $7.18 \cdot 10^{-3}$ \\
\hline 3. & 0.10 & $1.40 \cdot 10^{-2}$ & 14. & 0.65 & $7.87 \cdot 10^{-3}$ \\
\hline 4. & 0.15 & $8.64 \cdot 10^{-3}$ & 15. & 0.70 & $8.79 \cdot 10^{-3}$ \\
\hline 5. & 0.20 & $6.97 \cdot 10^{-3}$ & 16. & 0.75 & $1.01 \cdot 10^{-2}$ \\
\hline 6. & 0.25 & $6.25 \cdot 10^{-3}$ & 17. & 0.80 & $1.19 \cdot 10^{-2}$ \\
\hline 7. & 0.30 & $5.93 \cdot 10^{-3}$ & 18. & 0.85 & $1.46 \cdot 10^{-2}$ \\
\hline 8. & 0.35 & $5.82 \cdot 10^{-3}$ & 19. & 0.90 & $1.92 \cdot 10^{-2}$ \\
\hline 9. & 0.40 & $5.86 \cdot 10^{-3}$ & 20. & 0.95 & $2.84 \cdot 10^{-2}$ \\
\hline 10. & 0.45 & $6.02 \cdot 10^{-3}$ & 21. & 1.00 & - \\
\hline 11. & 0.50 & $6.29 \cdot 10^{-3}$ & - & - & - \\
\hline
\end{tabular}

Since 0.019 is significantly more than 0.006 , that is $\left(\chi_{P V C-T P U}\right)>\left(\chi_{P V C-T P U}\right)_{c r}$, then this system must be incompatible in a wide range of compositions. Using the equation

$$
\left(\chi_{A B}\right)_{s p}=\frac{1}{2} \cdot\left(\frac{1}{\left(\chi_{A}\left(\Phi_{A}\right)_{s p}\right)^{1 / 2}}+\frac{1}{\left(\chi_{B}\left(\Phi_{B}\right)_{s p}\right)^{1 / 2}}\right)^{2}
$$

we determine the probability of the phase separation origin, for which we calculate $\left(\chi_{P V C-T P U}\right)_{s p}$ for different phase compositions.

As seen, TPU dissolves in PVC much better than PVC, and at a content of less than $10 \%$ TPU, complete compatibility of the systems should be observed. The calculation shows that there is a so-called asymmetric case with two critical solution temperatures, the lower and the upper ones [12-16].

\section{Preparation and study of compositions}

Such compositions have a low relative elongation $(100 \ldots 200 \%$ at $293 \mathrm{~K})$, which is completely unsatisfactory for use in a number of RTG industries in particular for injection molded polyurethane tires manufacturing. For the purpose of imparting optimum technological and physical-mechanical properties to mixtures based on TPU, the modifying role of CCPE serving as a "carrier" for PVC incompatible with TPU was investigated.

The studies were conducted using $3^{2}$ full factorial design (FFD). Homogenization was carried out by mixing of research components on a double-roller mixer at a temperature of $438 \mathrm{~K}$ for 15 minutes, then the 
blades were injected which 7 days of exposure were subjected to rupture on a P- 0.5 tensile testing machine according to GOST $270-75$ at a drawing rate of $130 \mathrm{~mm} / \mathrm{min}$ and a temperature of $293 \mathrm{~K}$. Drawing on the literature data, optimal indicators for injection molded tires were determined: $d_{v}=1.0=45.0 \mathrm{kN} / \mathrm{m}$ is a tear resistance; $d_{\varepsilon}=1.0=375 \%$ is a relative elongation, where $d_{v}$ and $d_{\varepsilon}$ - desired factor functions.

The relationship of the desirability coefficient $y^{1}$ with the desirability function has the form:

$$
d=e^{-\left(y^{1}\right)^{n}}
$$

where $n$ is the exponent which value is determined by the requirement for the parameter.

Varying the indicator of desirability from -4 to +4 , we define the type of regression equation that relates the current value of the studied indicator with the indicator of desirability, referring to the equation:

where $y^{1}$ is the current value of the indicator.

$$
y_{\varepsilon}^{1}=\alpha_{0}+\alpha \cdot y^{1}
$$

The calculations found that:

$$
y_{\varepsilon}^{1}=-8.42+0.0276 \cdot y^{1}
$$

Taking the form of the desirability function $d=x / y^{1}$ according to [17-19], we determine the indicators of desirability for resistance to tearing $y_{\varepsilon}^{1}$ and relative elongation $y^{1}$, as well as the corresponding functions of desirability. The results are summarized in Tables 4 and 5.

Table 4

Desirability function and desirability indicators for breaking strength and relative elongation

\begin{tabular}{|c|c|c|c|c|}
\hline Item no. & $y_{i G}^{1}$ & $d_{i} G$ & $y_{i \varepsilon}^{1}$ & $d_{i} \varepsilon$ \\
\hline 1. & -2.78 & 0.01 & 4.78 & 1.0 \\
\hline 2. & -3.40 & 0.01 & 0.37 & 0.45 \\
\hline 3. & -2.97 & 0.01 & -3.40 & 0.01 \\
\hline 4. & -3.33 & 0.01 & 1.22 & 0.80 \\
\hline 5. & -3.25 & 0.01 & -3.23 & 0.01 \\
\hline 6. & -3.67 & 0.01 & 0.81 & 0.61 \\
\hline 7. & -2.99 & 0.01 & -0.98 & 0.01 \\
\hline 8. & -2.59 & 0.01 & -1.73 & 0.50 \\
\hline 9. & -2.84 & 0.01 & -3.23 & 0.01 \\
\hline 10. & - & - & - & - \\
\hline 11. & -3.84 & 0.01 & -2.19 & 0.02 \\
\hline 12. & -4.01 & 0.00 & -3.01 & 0.01 \\
\hline 13. & -3.01 & 0.01 & -0.49 & 0.20 \\
\hline 14. & -2.95 & 0.01 & 0.80 & 0.61 \\
\hline 15. & -2.44 & 0.01 & -2.69 & 0.01 \\
\hline 16. & -2.74 & 0.01 & -2.76 & 0.01 \\
\hline 17. & -2.93 & 0.01 & -2.41 & 0.01 \\
\hline 18. & -3.16 & 0.01 & -3.58 & 0.01 \\
\hline
\end{tabular}

The generalized desirability function was determined by the formula:

$$
D_{i}=\sqrt{d_{i} G \cdot \varepsilon} .
$$

The results of the physical-mechanical tests of the obtained compositions and the generalized desirability function are shown in Table 5 .

The analysis of tabular data shows that CCPE behaves as a typical polymeric plasticizer, due to the plasticizing effect of which the relative elongation of the composition increases by $2.5 \ldots 5$ times. The introduction of PVC enabled to reduce the negative impact of the plasticizing effect of CCPE on the breaking strength value. 
An analysis of generalized desirability functions shows that:

1) an increase in the PVC content from 5 to 10 by pts. wt. leads to an increase in $D_{i}$ from 0.067 to 0.078

2) an increase in the content of CCPE from 5 to 20 by pts. wt. leads to $D_{i}$ with an extremum at the level 12.5 pts. wt.

$$
\begin{array}{ll}
X_{2}=5 \text { pts. wt. } & D_{i}=0.067 ; \\
X_{2}=12.5 \text { pts. wt. }, & D_{i}=0.089 ; \\
X_{2}=20 \text { pts. wt. } & D_{i}=0.078 ;
\end{array}
$$

3 ) in one pair of the system (for example $3 a, 2 b$, etc.) is maximum with an increased content of petroleum resin PPC.

To study the polymer mixtures a polarizing microscope MIN-8 equipped with a purpose made photo nozzle with a Zenit-TTL reflex camera with magnification $\times 480$, quartz wedge $L=1 / 2 \lambda$ was used, polymer mixtures were studied at a temperature of $298 \mathrm{~K}$.

\begin{tabular}{|c|c|c|c|c|c|c|c|c|}
\hline \multirow[b]{2}{*}{ Item no. } & \multicolumn{4}{|c|}{ Variables } & \multicolumn{4}{|c|}{ Responses } \\
\hline & $\begin{array}{c}\text { Temperature } \\
\text { range, } \mathrm{K} \\
X_{0}\end{array}$ & PVC & ССРE & PPC & $\begin{array}{c}\text { Breaking } \\
\text { strength, } \\
\mathrm{MPa}, \\
y_{0}\end{array}$ & $\begin{array}{c}\text { Relative } \\
\text { elongation, } \\
\% \\
y_{1}\end{array}$ & $\begin{array}{c}\text { Remanent } \\
\text { elongation, } \\
\% \\
y_{2}\end{array}$ & $\begin{array}{c}\text { Generalized } \\
\text { desirability } \\
\text { function, } \\
D\end{array}$ \\
\hline 1a 1 & 373 & 5.0 & 5.0 & 0.55 & 20.4 & 354 & 57.5 & 0.1 \\
\hline $1 \mathrm{~b} 2$ & 373 & 5.0 & 5.0 & 2.2 & 18.2 & 477 & 89.5 & 0.067 \\
\hline $2 \mathrm{a} 3$ & 373 & 5.0 & 12.5 & 0.588 & 19.7 & 583 & 89.6 & 0.01 \\
\hline $2 \mathrm{~b} 4$ & 373 & 5.0 & 12.5 & 2.35 & 18.4 & 453 & 81.3 & 0.089 \\
\hline 3 a 5 & 373 & 5.0 & 20.0 & 0.626 & 18.7 & 578 & 89.8 & 0.01 \\
\hline $3 b 6$ & 373 & 5.0 & 20.0 & 2.5 & 17.2 & 510 & 77.1 & 0.078 \\
\hline $4 \mathrm{a} 7$ & 373 & 7.5 & 5.0 & 0.562 & 19.6 & 515 & 90.5 & 0.032 \\
\hline $4 \mathrm{~b} 8$ & 373 & 7.5 & 5.0 & 2.25 & 21.1 & 536 & 87.4 & 0.071 \\
\hline 5a 9 & 373 & 7.5 & 12.5 & 0.6 & 20.0 & 578 & 102.1 & 0.01 \\
\hline $5 b \quad 10$ & 373 & 7.5 & 12.5 & 2.4 & - & - & - & - \\
\hline 6a 11 & 373 & 7.5 & 20.0 & 0.638 & 16.5 & 549 & 91.5 & 0.014 \\
\hline 6b 12 & 373 & 7.5 & 20.0 & 2.55 & 15.9 & 572 & 106.4 & 0.00 \\
\hline $7 \mathrm{a} 13$ & 373 & 10.0 & 5.0 & 0.576 & 19.5 & 501 & 91.5 & 0.045 \\
\hline $7 \mathrm{~b} 14$ & 373 & 10.0 & 12.5 & 2.3 & 19.8 & 465 & 80.0 & 0.078 \\
\hline $8 \mathrm{a} 15$ & 373 & 10.0 & 12.5 & 0.612 & 21.6 & 563 & 91.5 & 0.01 \\
\hline $8 b \quad 16$ & 373 & 10.0 & 12.5 & 2.45 & 20.5 & 565 & 84.4 & 0.01 \\
\hline 9a 17 & 373 & 10.0 & 20.0 & 0.65 & 19.8 & 555 & 89.8 & 0.01 \\
\hline $9 \mathrm{~b} \quad 18$ & 373 & 10.0 & 20.0 & 2.6 & 19.1 & 588 & 89.6 & 0.01 \\
\hline
\end{tabular}

Table 5

Physical-mechanical properties and generalized desirability function of the composition

Investigation of solubility and thermodynamic parameters of polymer mixtures by method of inverse gas chromatography and turbidimetric titration (in block and solution)

The solubility parameters of substances characterize the relationship between the mixing energy and mutual solubility. The value of the solubility parameter of the polymer is necessary to obtain valuable information about the behavior of the polymer when mixed with other polymers or low molecular weight substances. By Hildebrand's definition, the solubility parameter is defined as the square root of the cohesive energy density, that is, the evaporation energy per unit of volume.

Direct determination of the heat of vaporization, and hence the solubility parameters of polymers are impossible due to their non-volatility. Presently, methods for determining the cohesive energy of polymers 


\section{Theory and Practice of Obtaining Composite Materials Based on Polymer Blends}

based on the examination of the interaction of a polymer-solvent with known solubility parameters became the most common.

The swelling of cross-linked polymers was studied in the research [20] and it was found that swelling is maximal in solvents that have the same cohesive energy density as the polymer. Bristow and Watson obtained the solubility parameters of polymers from measuring viscosity in a number of solvents using Flory-Huggins interaction parameters $\chi_{12}$. Furthermore, the solubility parameter of the polymer was assumed to be equal to the solubility parameter of the solvent, in which the limiting viscosity is maximum.

Small obtained additive molar attraction constants for various molecular groups from measurements of the vapor pressure of volatile substances and used these values to calculate the solubility parameters of the polymers. Subsequently, these constants were revised by Hoy and Van Krevelen.

Sokh and Clark proposed to determine the cohesive energy density from the data of turbidimetric titration (TT) of solutions by polyprecipators. The solubility parameters of polystyrene and poly-ochlorostyrene determined by them well correspond to the known values obtained from swelling measurements.

Ito and Gillet showed that when using polymers as the stationary phase and various sorbates with known solubility parameters, can be used inverse gas chromatography to determine the solubility parameters of polymers.

Both of the latter methods for determining the solubility parameters of polymers are characterized by the diametrically opposite state of the "polymer-solvent" system, namely, in the TT method the solubility parameter of the polymer is determined under conditions corresponding to the "infinite" dilution of the polymer in a solvent, which can be denoted as $\delta_{2}^{0}$. In the case of inversed gas chromatography, the solubility parameter is determined by the "infinite" dilution of the low molecular weight substance in the polymer and the maximum interaction between the polymer molecules. The solubility parameter is correctly designated as $\delta_{2}^{\infty}$.

Therefore, considering the presence of strong specific intermolecular interactions in polar polymers, we should expect an increase in the difference between $\delta_{2}^{0}$ and $\delta_{2}^{\infty}$ solvents and precipitators as the intermolecular interaction strength increases.

On the basis of Hildebrand-Scatchard and Flory theory, provided that the volume does not change when mixed, the parameter $\chi$ is related to the solubility parameter by the relation:

$$
\chi=\frac{V_{1}}{R \cdot T} \cdot\left(\delta_{1}-\delta_{2}\right)^{2}+\chi_{5}
$$

where $V_{1}$ is the molar volume of the solvent; $\delta_{1}$ and $\delta_{2}$ are the solubility parameters of the solvent and the polymer, respectively; $R, T$ are the gas constant and absolute temperature; $\chi_{5}$ is the entropic contribution to the interaction parameters.

Opening brackets and dividing variables, we have:

$$
\frac{\delta_{1}^{2}}{R \cdot T}-\frac{\chi}{V_{1}}=\frac{2 \cdot \delta_{1} \cdot \delta_{2}}{R \cdot T}-\left(\frac{\delta_{2}^{2}}{R \cdot T}+\frac{\chi_{5}}{V_{1}}\right)
$$

which is a linearized form of equation (2).

As established by Gray, the contribution of the $\chi / V$ term for good solvents (having least value $\chi$ for particular polymer) is insignificant and for these sorbates the linearization $\frac{\delta_{1}^{2}}{R \cdot T}-\frac{\chi}{V_{1}}$ relative to $\delta_{1}$ is not very different from a parabola.

Accordingly, the polymer solubility parameter $\delta_{i}^{\infty}$ can be found from the slope of the linear dependence $\frac{\delta_{1}^{2}}{R \cdot T}-\frac{\chi}{V_{1}}$ relative to a number of sorbates. The values in the left-hand side of the equation 
(3) can be found from the condition that samples in the vapor state behave like an ideal gas at infinite dilution. Then:

$$
\delta_{1}=\left(\frac{\Delta H_{v}-R \cdot T}{V_{1}}\right)^{0.5} .
$$

Here the values of the molar volume of the solvent $V_{1}$ and the heat of evaporation $\Delta H_{v}$ are easily determined or are available in the literature $[22 ; 23]$.

The Flory-Huggins interaction parameter is calculated using the equations proposed by Patterson and his co-workers

$$
\begin{gathered}
\ln \Omega^{\infty}=\ln \left(\frac{273.2 \cdot R}{P_{1}^{0} \cdot V_{g}^{0} \cdot M_{1}}-\frac{P_{1}^{0}}{R \cdot T \cdot\left(B_{i i}-V_{1}\right)}\right) ; \\
\chi_{12}^{\infty}=\ln \Omega^{\infty}-\ln \left(\frac{V_{1}}{V_{2}}-1+\frac{M_{1} \cdot v_{1}}{M_{2} \cdot v_{2}}\right),
\end{gathered}
$$

where $M_{1}, P_{1}^{0}, V_{1}, v_{1}$ are the molecular weight, saturated vapor pressure, molar and specific volumes of the solvent at temperature $T$, respectively; $B_{i i}$ is the second virial coefficient; $M_{2}, v_{2}$ are the molar weight of the segment and the specific volume of the polymer at $T ; V_{g}^{0}$ is the reduced to $273 \mathrm{~K}$ characteristic retention volume obtained in the usual way.

In return the values of $\chi$ in the case of titration with two different precipitants, one of which has a lower value $\delta_{1}\left(\chi_{C L}\right)$ and the other - a higher value of $\delta_{1}\left(\chi_{C h}\right)$ will be:

$$
\begin{gathered}
\chi_{C L}=\frac{V_{m L} \cdot\left(\delta_{2}-\delta_{m L}\right)_{C L}^{2}}{R \cdot T}+\left(\chi_{S}\right)_{C L} ; \\
\chi_{C h}=\frac{V_{m h} \cdot\left(\delta_{m h}-\delta_{2}\right)_{C h}^{2}}{R \cdot T}+\left(\chi_{S}\right)_{C h}
\end{gathered}
$$

Here the indices $m L$ and $m h$ are assigned to the mixture of solvent and precipitant at the turbidity point. Equating both expressions (5) and (6) to each other, taking $\left(\chi_{S}\right)_{C L}=\left(\chi_{S}\right)_{C h}$ for a low concentration of the polymer in the solution and solving for $\delta_{2}^{0}$, we have:

where

$$
\delta_{2}^{0}=\frac{\sqrt{V_{m L} \cdot \delta_{m L}}+\sqrt{V_{m h} \cdot \delta_{m h}}}{\sqrt{V_{m L}}+\sqrt{V_{m h}}},
$$

$$
\begin{aligned}
& V_{m}=\frac{V_{1} \cdot V_{3}}{\Phi_{1} \cdot V_{3}+\Phi_{3} \cdot V_{1}} ; \\
& \delta_{m}=\Phi_{1} \cdot \delta_{1}+\Phi_{3} \cdot \delta_{3} .
\end{aligned}
$$

Here $\Phi_{1}$ and $\Phi_{3}$ are the volume fractions of the solvent and precipitant in the solvent; $\delta_{1}$ and $\delta_{3}$ are the solubility parameters of the solvent and precipitant; $V_{1}, V_{3}$ are molar volumes of the solvent and precipitant.

Thereby, the values $\delta_{2}^{0}$ and $\delta_{2}^{\infty}$ can be determined from the experiment and, using the extrapolation method of reducing to the same temperature, we can compare them.

We have investigated industrial polymer samples, which were subjected to additional purification by reprecipitation of the wt \% solution in an appropriate solvent in the precipitant - standard, with a solventprecipitant relationship of 1:10.

As sorbates, solvents, and precipitators organic liquids of various chemical structures were used, the qualification was C.P. 


\section{Theory and Practice of Obtaining Composite Materials Based on Polymer Blends}

Studies using the IGC method were performed on a Tsvet-100 gas chromatograph with a flame ionization detector. Nitrogen was used as carrier gas. A solid carrier was a silanized carrier Chromaton N-AW-DMCS with a particle diameter of $0.20-0.25 \mathrm{~mm}$.

The nozzle was prepared by evaporation method. The solvents were: in the case of EPR - carbon tetrachloride, in the case of chlorocarboxylated LDPE (CCPE), chlorinated LDPE (CPE), PVC and PU tetrahydrofuran. The percentage of stationary phase in the nozzle was determined by sequential weighing after 1 week of polymer extraction in a Soxhlet extractor. We used stainless steel columns with a length of $1.0 \mathrm{~m}$, which were filled with nozzles containing polymers $10 \ldots 12 \mathrm{wt} \%$.

Characteristics of the columns are presented in Table 6.

Table 6

Characteristics of the columns

\begin{tabular}{|c|c|c|c|}
\hline \multirow{2}{*}{ Polymer } & $\begin{array}{c}\text { Nozzle weight in the column, } \\
\mathrm{g}\end{array}$ & $\begin{array}{c}\text { Polymer content in the nozzle, } \\
\%\end{array}$ & $\begin{array}{c}\text { Polymer mass in the column, } \\
\mathrm{g}\end{array}$ \\
\hline CCPE & 5.750 & 10.0 & 0.575 \\
\hline CPE & 4.520 & 10.1 & 0.558 \\
\hline PVC & 5.750 & 10.3 & 0.592 \\
\hline PU & 6.300 & 10.0 & 0.630 \\
\hline EPR & 4.802 & 10.7 & 0.514 \\
\hline
\end{tabular}

The experiments were carried out at $353,373,393 \mathrm{~K}$, which is higher than the glass transition temperature of all polymers. The sorbate sample volume was $0.02 \ldots 0.5 \mu l$. The value of the retention time ( $\delta$ interaction) was determined by gaseous methane.

Equilibrium values of retention volumes were obtained by extrapolation to zero flow rate of the gascarrier.

For the solubility parameter of polymers, solutions with a concentration of $0.05 \mathrm{~g} / \mathrm{dl}$ were prepared by the TT method. A precipitant was slowly added to the $15 \mathrm{ml}$ polymer solution while stirring.

The change in the optical density of the solution was recorded on a photoelectric colorimeter FEC-M, after which the precipitator concentration corresponding to the beginning of the precipitation polymerization (turbidity point) was determined by extrapolation to zero optical density. For the titration of polymer solutions at $298 \mathrm{~K}$, two different precipitants were used - one with a higher solubility parameter and the other with a lower solubility parameter.

Predictably, polar and non-polar chlorine derivatives of hydrocarbons turned out to be good solvents for CPE and CCPE.

Polar chlorinated hydrocarbon derivatives and ketones turned out to be good solvents for PU, and non-polar compounds for EPR. Notably, for all the polymers studied, tetrahydrofuran and chloroform proved to be good solvents at temperatures of 353...393 K. It is known [22; 23] that halogen atoms (or oxygen) activate a hydrogen atom and it becomes capable of forming hydrogen bonds, which are poorly realized between homogeneous molecules, what makes such compounds universal solvents of polymers. The small size of the molecules, which facilitates diffusion into the mass of the polymer is favorable for this.

After processing, the obtained values of $\frac{\delta_{1}^{2}}{R \cdot T}-\frac{\chi}{V_{1}}$ and $\delta_{1}$ for different classes of sorbates (saturated hydrocarbons, chlorine-containing hydrocarbons, ketones, alcohols, etc.) were smoothed over the aggregate data set of the straight line $y=A+B \cdot X$, after which were calculated $\delta_{2}^{\infty}$ and the mean square error $\sigma^{2}$. The results are summarized in Table 7 .

The contribution of $\frac{\chi_{12}^{\infty}}{V}$ in $\frac{\delta}{R \cdot T}-\frac{\chi}{V_{1}}$ is different for a number of sorbates used, the value of which also varies with temperature. 
The solubility parameters of polymers $\delta_{2}^{0}$ and $\delta_{2}^{\infty}$

\begin{tabular}{|c|c|c|c|c|c|}
\hline \multirow{2}{*}{ Polymer } & \multicolumn{3}{|c|}{$\delta_{2}^{0}$} & $\delta_{2}^{\infty}$ & \multirow{2}{*}{ Experim. 298 K } \\
\cline { 2 - 5 } & $393 \mathrm{~K}$ & $373 \mathrm{~K}$ & $353 \mathrm{~K}$ & Calculation $298 \mathrm{~K}$ & \\
\hline CCPE & $6.75 \pm 0.31$ & $7.26 \pm 0.49$ & $7.75 \pm 0.33$ & $9.16 \pm 0.36$ & $9.86 \pm 0.35$ \\
\hline CPE & $7.11 \pm 0.49$ & $7.53 \pm 0.56$ & $7.93 \pm 0.44$ & $9.06 \pm 0.50$ & $9.91 \pm 0.35$ \\
\hline PU & $7.06 \pm 0.57$ & $7.50 \pm 0.41$ & $8.05 \pm 0.65$ & $9.49 \pm 0.55$ & $12.07 \pm 0.35$ \\
\hline EPR & $7.11 \pm 0.15$ & $7.36 \pm 0.57$ & $7.59 \pm 0.11$ & $8.25 \pm 0.28$ & $8.55 \pm 0.35$ \\
\hline PVC & $7.11 \pm 0.51$ & $7.52 \pm 0.56$ & $7.91 \pm 0.98$ & $9.14 \pm 0.42$ & $9.89 \pm 0.35$ \\
\hline
\end{tabular}

Therefore, by the criterion of the contribution $\chi / V_{1}$ we selected for CCPE -7 sorbates, PU -7 sorbates, CPE -6 sorbates and EPR -7 sorbates, which were used to calculate $\delta_{2}^{\infty}$.

As can be seen, all $\delta_{2}^{\infty}$ values are a decreasing function of temperature, which allows extrapolating the obtained results to $469 \mathrm{~K}$ with sufficient confidence [11-16].

The obtained value $\delta_{2}^{\infty}=8.25 \pm 0.28$ for the EPR was in fairly good agreement with $\delta_{2}^{\infty}=7.70 \pm 0.11$ obtained by the IGC method considering the influence of the nature and composition of the polymer on its solubility parameter.

It should be noted that the measurement error increases with an increase in the number of functional groups in the macromolecule, reaching a maximum value for PU.

It is demonstrated that in all cases the $\delta_{2}^{0}$ values obtained from the titration data in aliphatic solvents are more widely scattered and consistently lower than the values obtained from the titration data in aromatic solvents. Hildebrant showed that good agreement with experiment can also be obtained for hydrocarbons if we assume that the values of their solubility parameters are 0.6 higher than those calculated from the evaporation energy. Nevertheless, an amendment to $\delta_{1}$ of about 0.3 was practically required. This creates uncertainties in the value of $\delta_{2}^{0}$ for aliphatic solvents leading however to an error in determining $\delta_{2}^{0}$ not more than \pm 0.35 . This value of the error was taken for all determinations of the solubility parameters of polymers by the method of TT.

The change in $\chi_{1(23)}^{\infty}$ with the composition for the CCPE-CPE-PVC systems is shown in Fig. 1.
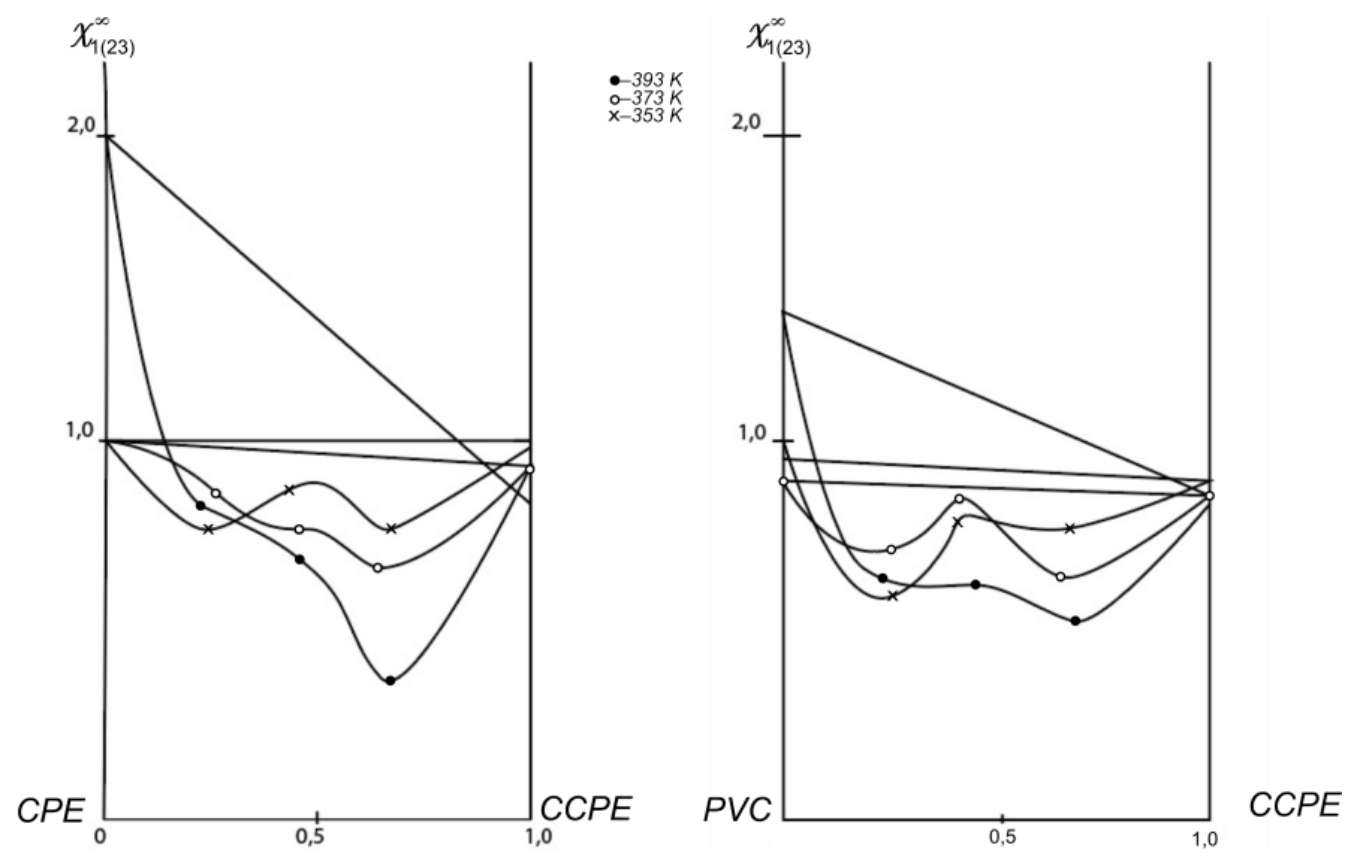

Fig. 1. The change in $\chi_{1(23)}^{\infty}$ with the composition for the CCPE-CPE-PVC systems 


\section{Theory and Practice of Obtaining Composite Materials Based on Polymer Blends}

There is a definite trend to increase the difference between $\delta_{2}^{0}$ and $\delta_{2}^{\infty}$ denoted as $\Delta \delta_{2}^{0 / \infty}$ as the number of polar groups increases.

Thus, if for a practically non-polar polymer - EPR the value $\chi_{1(23)}^{\infty}$ fits into the experimental error $\Delta \delta_{2}^{0 / \infty}$, then for CCPE and CPE, which contain highly polar chloromethylene groups, the halogen of which is able to activate a hydrogen atom to form a hydrogen bond, the solubility parameters differ by an amount significantly higher than the instrumental error and $\Delta \delta_{2}^{0 / \infty}=0.7 \ldots 0.8$. In the event of a highly polar PU polymer having a large amount of hydrogen bonds like NH...O, the difference in solubility parameters reaches a very large value $\Delta \delta_{2}^{0 / \infty}=2.58$ (for example: in the form of a dimer, acetic acid has $\delta_{1}=9.19$, while in the form of a monomer, $\delta_{1}=13.01$ ). The calculations are presented in Table 8 .

Consequently, an experimental comparison of the values of solubility parameters of polymers, obtained by two methods IGC and TT, characterized by an extremely opposite state of the polymer in relation to the solvent, showed a significant difference in solubility parameters for polymers with strong specific interactions between macromolecules, which requires attention when using the solubility parameter theory to predict the compatibility of polymer pairs to the method by which the used value is obtained. It is apparent that for crystallizing polymers there should also be a difference in solubility parameters.

Thus, having determined two values of the solubility parameter by the TT and IGC method, it can be said that to predict the solubility parameter of such polymers as CCPE, CPE, PU, EPR and PVC, both of these values should be used [8-14].

Table 8

Calculation of solubility parameters of polymers with each other at different temperatures

\begin{tabular}{|c|c|c|c|c|c|c|c|c|c|c|c|c|}
\hline \multirow{2}{*}{ Substance } & \multicolumn{4}{|c|}{$393 \mathrm{~K}$} & \multicolumn{4}{|c|}{$473 \mathrm{~K}$} & \multicolumn{4}{|c|}{$353 \mathrm{~K}$} \\
\cline { 2 - 15 } & CCPE & CPE & PU & EPR & CCPE & CPE & PU & EPR & CCPE & CPE & PU & EPR \\
\hline Methanol & 2.083 & 2.294 & 1.829 & 2.780 & 2.634 & 2.52 & 1.951 & 2.857 & 3.097 & 2.921 & 1.881 & 3.232 \\
\hline Etanol & 2.057 & 2.225 & 2.038 & 2.291 & 2.272 & 2.311 & 1.462 & 2.333 & 2.892 & 2.644 & 1.734 & 2.712 \\
\hline Pentane & 0.887 & 1.702 & 1.950 & 0.752 & 1.318 & 1.460 & 0.707 & 0.730 & 1.197 & 1.725 & 1.369 & 0.825 \\
\hline DEE & 0.651 & 2.349 & 1.081 & 0.617 & 0.895 & 1.217 & 1.207 & 0.638 & 0.977 & 1.261 & 0.933 & 0.610 \\
\hline CP & 0.746 & 2.112 & 0.809 & 0.526 & 0.819 & 0.892 & 0.543 & 0.452 & 0.883 & 0.883 & 0.436 & 0.530 \\
\hline Acetone & 1.321 & 0.250 & 1.155 & 1.778 & 1.509 & 1.261 & 1.093 & 1.274 & 1.501 & 1.342 & 1.046 & 1.276 \\
\hline Hexane & 0.566 & 1.649 & 1.713 & 0.809 & 1.331 & 1.237 & 1.539 & 0.812 & 1.298 & 1.761 & 1.463 & 0.837 \\
\hline EDC & 0.947 & 1.114 & 0.917 & 0.553 & 0.987 & 1.160 & 0.795 & 0.262 & 1.038 & 1.137 & 0.792 & 0.457 \\
\hline CCl 4 & 0.867 & 1.094 & 1.472 & 0.729 & 1.069 & 1.118 & 1.299 & 0.740 & 1.245 & 1.166 & 1.165 & 0.741 \\
\hline THF & 0.647 & 0.923 & 0.949 & 0.543 & 0.678 & 0.754 & 0.829 & 0.522 & 0.756 & 0.725 & 0.709 & 0.362 \\
\hline
\end{tabular}

With a view to examine the processing conditions of the compositions based on the studied polymers, work was done to determine the influence of the mixing temperature on the physicomechanical properties of the compositions: $\mathrm{PVC}+\mathrm{CCPE}, \mathrm{TPU}+\mathrm{PVC}, \mathrm{BR}+\mathrm{PVC}+\mathrm{CCPE}, \mathrm{TPU}+\mathrm{PVC}+\mathrm{CCPE}+\mathrm{PPC}$.

The data obtained are shown in Tables 9, 10 and 11

Concerning question of reducing or raising the temperature, in the first case, along with a decrease in temperature, which is considered to be a desirable element in terms of processing, there is also a decrease in physical-mechanical parameters, moreover, the test film has an unattractive appearance, turbidity is observed and there is an attachment of unmelted polymer particles. As the temperature increases, processes of destruction develop, a reddening of the film is observed, which is explained by the formation of polyene segments in the PVC macromolecule.

Thus, the processing interval for PVC modified by chlorocarboxylate polyethylene should be considered as the temperature range between $416-423 \mathrm{~K}$.

Reducing the concentration of the modifier leads to the loss of a number of valuable properties of modified PVC. The decrease in elasticity is observed and the incombustibility is lost. A preliminary 
assessment of the PVC film prototypes on resistance to aggressive effects (sulfuric acid, hydrochloric acid), as well as a number of solvents indicates the favorable impact of the introduction of CCPE+PVC.

Table 9

Physical-mechanical properties of the developed composition based on PVC

\begin{tabular}{|c|c|c|c|c|c|}
\hline Composition & $\begin{array}{c}\text { Onset } \\
\text { temperature, } \mathrm{K}\end{array}$ & $\begin{array}{c}\text { Breaking } \\
\text { strength, MPa }\end{array}$ & $\begin{array}{c}\text { Relative } \\
\text { elongation, } \%\end{array}$ & $\begin{array}{c}\text { Residual } \\
\text { elongation, } \%\end{array}$ & $\begin{array}{c}\text { Tear resistance, } \\
\mathrm{MPa}\end{array}$ \\
\hline $\begin{array}{c}\text { Original } \\
\text { PVC }\end{array}$ & 431 & 16.7 & 10.0 & 4.0 & 4.3 \\
\hline PVC+CCPE & 463 & 18.7 & 20.0 & 12 & 5.9 \\
\hline
\end{tabular}

Table 10

Physical-mechanical properties of composition based on PU

\begin{tabular}{|c|c|c|c|c|}
\hline Item No. & Composition & Weight fraction & Breaking strength, MPa & Relative elongation, \% \\
\hline \multirow{3}{*}{1.} & PU & 87 & 18 & 230 \\
\cline { 2 - 5 } & PVC & 10 & - & - \\
\cline { 2 - 5 } & PPC & 3 & - & - \\
\hline \multirow{3}{*}{2.} & PU & 93 & 20 & 280 \\
\cline { 2 - 5 } & PVC & 5 & - & - \\
\cline { 2 - 5 } & PPC & 2 & - & - \\
\hline 3. & PU & 100 & 17 & 150 \\
\hline
\end{tabular}

Table 11

Physical-mechanical characteristics of the developed compositions based on polyurethane (PU)

\begin{tabular}{|l|c|c|c|}
\hline \multirow{2}{*}{ Parameter name } & \multicolumn{3}{|c|}{ System, the ratio of components, weight fraction } \\
\cline { 2 - 4 } & $\begin{array}{c}\text { PU+PVC+CCPE } \\
80: 10: 10\end{array}$ & $\begin{array}{c}\text { PU+PVC+CCPE } \\
70: 10: 20\end{array}$ & $\begin{array}{c}\text { PU+PVC+ CCPE } \\
90: 6: 4\end{array}$ \\
\hline Tensile strength, $\mathrm{MPa}\left(\mathrm{kgf} / \mathrm{cm}^{2}\right)$ & 42 & 38 & 36 \\
\hline Relative elongation, \% & 90 & 100 & 120 \\
\hline Combustibility & burns & burns & fades away \\
\hline Breaking temperature, K & 523 & 533 & 543 \\
\hline
\end{tabular}

\section{Conclusions}

Based on the conducted study of the compatibility of polymers in various systems of thermodynamic, chemical and other features, we can point to the conclusion:

a) compositions based on TPU and PVC are used for the manufacture of molded tires, centralizers on the casing strings, pneumatic rings for pneumatic radiators, etc.;

b) compositions based on $\mathrm{BR}+\mathrm{PE}+\mathrm{PVC}+\mathrm{EPR}+\mathrm{CCPE}$ are recommended for production a nuclear (magnetic) logging probe, a tiering surface for grain cleaning machines, elevator buckets.

\section{References}

[1] F. A. Amirov, K. S. Shikhaliyev, U. T. Ahmadova, "Chemical Modification Of Oxidized Polymers", International Journal of Development Research, vol. 08, issue 07, pp. 21902-21906, July, 2018.

[2] K. S. Shikaliyev, Monomers for the synthesis of polymers. Saarbrücken, Germany: Lambert Academic Publishing, 2017.

[3] K. S. Shikaliyev, "Obtaining an ecological pure composition based on polyvinyl chloride and benzylnaphthanate ether obtained from Baku oil", in Proc. Int. Conf. "World Science”, Dubai, UAE, 2017, vol. 1, pp. $46-48$.

[4] K. S. Shikhaliyev, "Exploited thermoplastics based compositions", European Science Review, issue 5-6, pp. 88-92, 2017.

[5] K. S. Shikhaliyev, N. A. Salimova, "Thermodinamics and mutual distribution of macromolecules in the systems: chlorine-chlorocontaining polymers", European Science Review, issue 3-4, pp. 118-119, 2017. 


\section{Theory and Practice of Obtaining Composite Materials Based on Polymer Blends}

[6] M. Forrest, "The Composition and Nature of Vulcanisation Fumes in the Rubber Industry - A Technical Review", Progress in Rubber Plastics Recycling Technology, vol. 31, issue 4, pp. 219-264, 2015.

[7] Waleed A. Hussain, Abdullah A. Hussein, Jabar M. Khalaf, Ali H. Al-Mowali, Abdulwahab A. Sultan, "Dielectric Properties and a.c. Conductivity of Epoxy/Alumina Silicate NGK Composites", Advances in Chemical Engineeing and Scince, vol. 5, issue 3, pp. 282-289, 2015.

[8] P. Sarkar, N. Modak, P. Sahoo, "Mechanical Characteristics of Aluminium Powder Filled Glass Epoxy Composites”, International Journal of Engineering and Technologies, vol. 12, pp. 1-14, 2017.

[9] K. Sai Sravani, B. Ram Gopal Reddy, Raffi Mohammed, "Effect of $\mathrm{CaCO}_{3}$ and $\mathrm{Al}_{2} \mathrm{O}_{3}$ Fillers on Mechanical Properties of Glass/Epoxy Composites", International Journal for Modern Trends in Science and Technology, vol. 03, issue 06, pp. 207-213, June, 2017.

[10] V. N. Kuleznev, P. V. Surikov, "Fazovyye ravnovesiya v trekhkomponentnykh smesyakh polimerov" ["Phase equilibria in ternary polymer blends"], Vysokomolekulyarnyye soyedineniya. Seriya A [Polymer Science. Series A], vol. 54, no. 11, pp. 833-839, 2012. [in Russian].

[11] M. Mulder, Basic Principles of Membrane Technology. Dordrecht, the Netherlands: Kluwer Academic, 1996.

[12] N. A. Belov, A. P. Safronov, Y. P. Yampolskii, "Obrashchennaya gazovaya khromatografiya i termodinamika sorbtsii v polimerakh" ["Inverse-gas chromatography and the thermodynamics of sorption in polymers"], Vysokomolekulyarnyye soyedineniya. Seriya A [Polymer Science. Series A], vol. 54, no. 11, pp. 859-873, 2012. [in Russian].

[13] I M. Arcana, B. Bundjali, I. Yudistira, B. Jariah, L. Sukria, Study on Properties of Polymer Blends from Polypropylene with Polycaprolactone and Their Biodegradability, Polymer Journal, vol. 39, no. 12, pp. 1337-1344, 2007.

[14] E. A. Ermilova, A. A. Sizova, N. N. Il'icheva, D. V. Pleshakov, "Issledovaniye termodinamicheskoy sovmestimosti trekhkomponentnoy smesi nitraminov s sopolimerom metilmetakrilata i metakrilovoy kisloty" ["Investigation of thermodynamic compatibility of three components mixture of nitramine with copolymer methyl methacrylate and methacrylic acid"], Uspekhi v Khimii $i$ Khimicheskoy Tekhnologii [Success in Chemistry and Chemical Technology], vol. 28, issue 2 (151), pp. 65-67, 2014. [in Russian].

[15] Yu. M. Zuyev, Dostizheniya nauki i tekhnologii v oblasti reziny [Advances in Rubber Science and Technology]. Moscow, Russia: Khimiia Publ., 1959. [in Russian].

[16] A. E. Portyanskiy, Yo. Abrakham, G. L. Alizade, Ya. M. Bilalov, "Issledovaniye protsessa mekhanoinitsiirovannoy modophikatsii SKEP s PVKH" ["Investigation of the process of mechanized initiation of EPDM with PVC"], Azerbaydzhanskiy khimicheskiy zhurnal [Azerbaijan Chemical Journal], no. 4, pp. 80-85, 1975. [in Russian].

[17] O. A. Serenko, G. P. Goncharuk, et al., "Vliyaniye temperaturi na deformatsionnoye povedeniye kompozita na osnove plipropilena i chastits rezini" ["Effect of temperature on the stress-strain behavior of a polypropylene-particulate rubber composite"], Vysokomolekulyarnyye soyedineniya. Seriya A [Polymer Science. Series A], vol. 49, no. 1, pp. 71-78, 2007. [in Russian].

[18] I. Ya. Derikov, I. Yu. Kutergina, et al., "Stable nonequilibrium composites based on liquid-crystalline polymers and cadmium selenide nanoparticles", Vysokomolekulyarnyye soyedineniya. Seriya A [Polymer Science. Series A], vol. 56, no. 4, pp. 488-497, 2014. [in Russian].

[19] A. E. Zaikin, G. B. Bobrov, "Kompatibilizasiya smesey nesovmestimikh polimerov napolneniyem" ["Compatibility of mixtures of incompatible polymers by filling"], Vysokomolekulyarnyye soyedineniya. Seriya A [Polymer Science. Series A], vol. 54, no. 8, pp. 1275-1282, 2012. [in Russian].

[20] S. H. El-Sabbagh, "Compatibility study of natural rubber and ethylene-propylene-diene rubber blends", Applied polymer science, vol. 90, no. 1, pp. 1-11, October, 2003.

[21] A. A. Askadskii, "Vliyaniye silnikh mezhmolekulyarnikh i khimicheskikh vzaimodeystviy na sovmestimost polimerov" ["The effect of strong intermolecular and chemical interactions on the compatibility of polymers"], Uspekhi khimii [Russian Chemical Reviews], 1999, vol. 68, no. 4, pp. 349-364. [in Russian].

[22] A. Amash, R. H. Schuster, T. Früh, "Effects of compatibility in rubber/polypropilene blends", Elastomere und Kunststoffe [Elastomers and Plastics], no.6, pp. 315-320, 2001.

[23] M. O. Abou-Helal, S. H. El-Sabbagh, "Study on the compatibility of NR-EPDM blends using electrical and mechanical techniques", Journal of Elastomers and Plastics, vol. 37, no. 4, pp. 319-346, 2005. 